Research Paper

\title{
Comparison of clinical characteristics among younger and elderly deceased patients with COVID-19: a retrospective study
}

\author{
Xueyun Tan ${ }^{1,{ }^{*}}$, Shuai Zhang ${ }^{1, *}$, Juanjuan Xu ${ }^{1,{ }^{*}}$, Mei Zhou ${ }^{1}$, Qi Huang ${ }^{1}$, Limin Duan ${ }^{1}$, Zhilei Lv $^{1}$, Hui \\ $\mathrm{Xia}^{1}$, Wenjing Xiao ${ }^{1}$, Zhengrong Yin ${ }^{1}$, Yang Jin $^{1}$ \\ ${ }^{1}$ Department of Respiratory and Critical Care Medicine, Union Hospital, Tongji Medical College, Huazhong \\ University of Science and Technology, Wuhan, China \\ *Equal contribution
}

Correspondence to: Yang Jin; email: whuhjy@126.com, https://orcid.org/0000-0003-2409-7073

Keywords: COVID-19, SARS-CoV-2, age, comorbidity, complication

Received: May 30, $2020 \quad$ Accepted: October 9, 2020

Published: December 11, 2020

Copyright: (C) 2020 Tan et al. This is an open access article distributed under the terms of the Creative Commons Attribution License (CC BY 3.0), which permits unrestricted use, distribution, and reproduction in any medium, provided the original author and source are credited.

\section{ABSTRACT}

We aimed to compare the age-related clinical characteristics between younger and elderly deceased COVID-19 patients. This single-center retrospective study included 163 adult deceased COVID-19 patients who were admitted to Wuhan Union Hospital West Campus from January 12, 2020, to March 30, 2020. Demographic and clinical features were collected by reviewing the medical records. The median age of the 163 deceased patients was 69 (interquartile range [IQR], 62-78) years. They were classified as younger (age $18-69$ years; $86 / 163,52.8 \%$ ) and elderly ( $\geq 70$ years; $77 / 163,47.2 \%$ ) subjects. Younger deceased patients were more likely to develop fever $(72 / 86$ vs $54 / 77, P=0.039)$ than elderly deceased patients were while anorexia was $(29 / 77$ vs $19 / 86, P=0.029)$ more common in elderly deceased patients than in younger deceased patients. In multivariate analyses, age was a protective factor for acute cardiac injury of deceased COVID-19 patients (odds ratio [OR] 0.968, [95\% confidence interval (CI), 0.940-0.997]; $P=0.033$ ) while chronic cardiac disease was a risk factor for acute cardiac injury of deceased COVID-19 patients (OR $2.660[95 \% \mathrm{Cl}, 1.034-6.843] ; \mathrm{P}=0.042$ ). Our study described the clinical characteristics of younger and elderly deceased COVID-19 patients and demonstrated that younger deceased patients were more likely to develop an acute cardiac injury.

\section{INTRODUCTION}

Since December 2019, an ongoing outbreak of Coronavirus disease 2019 (COVID-19) has struck Wuhan, China [1]. As of August 23, 2020, COVID-19 has affected over 23057288 individuals in more than 200 countries, and resulted in more than 800000 deaths worldwide [2]. The mortality rate in China was reported to be $5.45 \%$ as of August 24, 2020 [3]. However, the mortality rate of critically ill COVID-19 patients was extremely high [4]. Many studies revealed that age and comorbidities such as hypertension and chronic cardiac disease were risk factors for mortality of COVID-19 patients [5-9].
Meanwhile, respiratory and cardiac complications were more frequent in non-survivors than in survivors [10]. A previous study indicated that COVID-19 patients order than 70 years old were more likely to hospitalized [11]. Another study, however, showed that age $\geq 70$ was an independent risk factor for inhospital death of COVID-19 patients with diabetes [12]. However, the differences between younger and elderly COVID-19 deceased patients are still unknown. This study aimed at comparing the clinical differences between younger and elderly COVID-19 deceased patients and to provide insights on the relationship between age and death in patients with COVID-19. 


\section{RESULTS}

\section{Clinical characteristics of younger and elderly deceased patients}

As shown in Table 1, 163 deceased patients were recruited into the study. Among whom 109 were male and 54 were female. The median age of all the 163 deceased patients was 69.0 (IQR 62.0-78.0) years. Further, the patients were divided into two groups according to the median age. Of these, $86(52.8 \%)$ patients were classified as younger (1869 years old) subjects, and $77(47.2 \%)$ patients were classified as elderly ( $\geq 70$ years old) subjects. The most common presenting symptoms were fever (126 [77.3\%]), dyspnea (113 [69.3\%]), and cough (104 [63.8\%]). Other common symptoms include fatigue, shortness of breath, sputum production, anorexia, myalgia, and diarrhea. Younger deceased patients were more likely to develop fever than elderly deceased patients (72/86 vs 54/77, $\mathrm{P}=0.039$ ) while anorexia was more common in elderly deceased patients than in the younger deceased patients ( $29 / 77$ vs $19 / 86, P=0.029$ ). It was established that the median time from onset of illness to death was 25.0 (IQR 18.0-35.0) days and 22.0 (IQR 15.0-33.5) days in younger deceased patients and elderly deceased patients respectively.

The vital signs of the 163 deceased patients on admission are shown in Table 1. The systolic blood pressure of elderly deceased patients was higher than younger deceased patients $(\mathrm{P}=0.012)$. However, the heart rate of younger deceased patients was faster than that of the older deceased patients $(\mathrm{P}=0.017)$. No significant differences were seen in any other vital signs between the two groups. The most common comorbidities in younger deceased patients were hypertension (31.4\%), diabetes (18.6\%), and malignancy $(11.6 \%)$, while in elderly deceased patients, hypertension (46.8\%), chronic cardiac disease $(22.1 \%)$ and diabetes (18.2\%) were most common comorbidities. Elderly deceased patients showed more presence of hypertension $(36 / 77 \quad$ vs $27 / 86, \quad \mathrm{P}=0.044)$, chronic obstructive pulmonary disease (COPD) (4/77 vs 0/86, $\mathrm{P}=0.048)$, and chronic cardiac disease ( $17 / 77$ vs $8 / 86$, $\mathrm{P}=0.024)$ than younger deceased patients did. The quick Sequential Organ Failure Assessment (qSOFA) score and CURB-65 pneumonia severity score were used to evaluate the severity of pneumonia in patients on admission. No significant differences were seen between younger and elderly deceased patients using the qSOFA score and CURB-65 score.

\section{Laboratory and radiographic findings of younger and elderly deceased patients on admission}

The laboratory findings of the 163 deceased patients on admission are shown in Table 2. 138 (84.7\%) patients presented with a lymphocyte count below the normal range $\left(1.1-3.2 \times 10^{9}\right.$ cells $\left./ \mathrm{L}\right)$ and $97(59.5 \%)$ patients had neutrophil count above the normal range (1.8$6.3 \times 10^{9}$ cells/L). Moreover, $153(93.7 \%)$ patients had elevated C-reactive protein (CRP) $(>8 \mathrm{mg} / \mathrm{L})$ and 145 $(89.0 \%)$ patients had increased lactate dehydrogenase levels (>245U/L).

The blood eosinophil count of younger deceased patients was much lower than elderly deceased patients $(\mathrm{P}=0.019)$. Compared to younger deceased patients, elderly deceased patients had notably higher levels of creatinine $(\mathrm{P}=0.001)$, blood urea nitrogen $(\mathrm{P}=0.016)$, uric acid $(\mathrm{P}<0.001)$, myoglobin $(\mathrm{P}=0.015)$, and hypersensitive cardiac troponin I $(\mathrm{P}=0.017)$ than younger deceased patients did. Moreover, the activated partial thromboplastin time of elderly deceased patients was significantly longer than that of younger deceased patients $(\mathrm{P}=0.022)$.

Besides, a chest CT scan was conducted on 74 younger and 65 elderly deceased patients four days before or after hospitalization (Table 3). 116 (83.5\%) deceased patients showed bilateral lung involvement and 113 $(81.3 \%)$ patients had a lung involvement ratio of more than $30 \%$. The most common findings on chest CT scans were ground-glass opacity $(128 / 139,92.1 \%)$ and consolidation $(125 / 139,89.9 \%)$.

\section{Univariate and multivariate analysis for complications in younger and elderly deceased patients}

The most commonly observed complication, among the 163 deceased patients, was acute respiratory distress syndrome (ARDS) (97.5\%), followed by respiratory failure (74.2\%), acute cardiac injury (36.8\%), septic shock (34.4\%), and acute kidney injury (21.5\%) (Table 4). The comparison between complications in younger and elderly deceased patients is shown in Table 4 . There were no significant differences observed in complications between younger and elderly deceased patients.

Subsequently, we analyzed the factors associated with acute cardiac injury and septic shock in COVID-19 deceased patients by using a logistic regression model. In multivariable analyses, age was a protective factor for acute cardiac injury of COVID-19 deceased patients (odds ratio [OR] 0.968, [95\% confidence interval (CI), 0.940-0.997]; $\mathrm{P}=0.033$ ) while the chronic cardiac disease was a risk factor for acute cardiac injury of COVID-19 deceased patients (OR 2.660 [95\%CI, 1.034-6.843]; $\mathrm{P}=0.042$ ) (Table 5). Bacterial infections (aOR 66.304, [95\% CI, 8.490-517.785]; $\mathrm{P}<0.001)$ and fungal infections (aOR 8.946, [95\% CI, 1.654-48.380]; 
Table 1. Clinical characteristics of younger and elderly deceased patients with COVID-19.

\begin{tabular}{|c|c|c|c|c|}
\hline Characteristics & Total $(n=163)$ & Younger $(n=86)$ & Elderly $(n=77)$ & P value \\
\hline Age, years & $69.0(62.0-78.0)$ & $62.0(57.0-66.0)$ & $78.0(73.0-83.0)$ & $<0.001^{*}$ \\
\hline Male Sex & $109(66.9 \%)$ & $58(67.4 \%)$ & $51(66.2 \%)$ & $0.870 \%$ \\
\hline \multicolumn{5}{|l|}{ Comorbidities } \\
\hline Hypertension & $63(38.7 \%)$ & $27(31.4 \%)$ & $36(46.8 \%)$ & $0.044 \hbar$ \\
\hline Diabetes & $30(18.4 \%)$ & $16(18.6 \%)$ & $14(18.2 \%)$ & $0.945 \$$ \\
\hline COPD & $4(2.5 \%)$ & $0(0.0 \%)$ & $4(5.2 \%)$ & $0.048 \S$ \\
\hline Chronic cardiac disease & $25(15.3 \%)$ & $8(9.3 \%)$ & $17(22.1 \%)$ & $0.024 \hbar$ \\
\hline Chronic hepatic disease & $3(1.8 \%)$ & $2(2.3 \%)$ & $1(1.3 \%)$ & $1.000 \S$ \\
\hline Chronic renal disease & $10(6.1 \%)$ & $3(3.5 \%)$ & $7(9.1 \%)$ & $0.193 \S$ \\
\hline Cerebrovascular disease & $11(6.7 \%)$ & $4(4.7 \%)$ & $7(9.1 \%)$ & $0.259 \$$ \\
\hline Malignancy & $18(11.0 \%)$ & $10(11.6 \%)$ & $8(10.4 \%)$ & $0.801 \%$ \\
\hline Anemia & $5(3.1 \%)$ & $3(3.5 \%)$ & $2(2.6 \%)$ & $1.000 \S$ \\
\hline \multicolumn{5}{|l|}{ Symptoms on admission } \\
\hline Fever & $126(77.3 \%)$ & $72(83.7 \%)$ & $54(70.1 \%)$ & $0.039 \$$ \\
\hline Fatigue & $92(56.4 \%)$ & $51(59.3 \%)$ & $41(53.2 \%)$ & $0.436 \%$ \\
\hline Myalgia & $36(22.1 \%)$ & $20(23.3 \%)$ & $16(20.8 \%)$ & $0.704 \hbar$ \\
\hline Cough & $104(63.8 \%)$ & $58(67.4 \%)$ & $46(59.7 \%)$ & $0.307 \hbar$ \\
\hline Sputum production & $65(39.9 \%)$ & $33(38.4 \%)$ & $32(41.6 \%)$ & $0.678 \%$ \\
\hline Dyspnea & $113(69.3 \%)$ & $57(66.3 \%)$ & $56(72.7 \%)$ & $0.373 \%$ \\
\hline Nausea & $6(3.7 \%)$ & $4(4.7 \%)$ & $2(2.6 \%)$ & $0.685 \S$ \\
\hline Vomiting & $6(3.7 \%)$ & $4(4.7 \%)$ & $2(2.6 \%)$ & $0.685 \S$ \\
\hline Abdominal pain & $5(3.1 \%)$ & $3(3.5 \%)$ & $2(2.6 \%)$ & $1.000 \S$ \\
\hline Diarrhea & $27(16.6 \%)$ & $16(18.6 \%)$ & $11(14.3 \%)$ & $0.459 \ddagger$ \\
\hline Anorexia & $48(29.4 \%)$ & $19(22.1 \%)$ & $29(37.7 \%)$ & $0.029 \ddagger$ \\
\hline Headache & $5(3.1 \%)$ & $4(4.7 \%)$ & $1(1.3 \%)$ & $0.371 \S$ \\
\hline Shortness of breath & $66(40.5 \%)$ & $34(39.5 \%)$ & $32(41.6 \%)$ & $0.793 \%$ \\
\hline Days from illness onset to admission & $10.0(7.0-15.0)$ & $11.0(8.8-15.0)$ & $10.0(6.0-15.0)$ & $0.084^{*}$ \\
\hline Days from illness onset to death & $23.0(17.0-34.0)$ & $25.0(18.0-35.0)$ & $22.0(15.0-33.5)$ & $0.355^{*}$ \\
\hline \multicolumn{5}{|l|}{ Vital signs on admission } \\
\hline Body temperature, ${ }^{\circ} \mathrm{C}$ & $36.9(36.5-37.8)$ & $37.0(36.5-38.0)$ & $36.8(36.5-37.5)$ & $0.342 *$ \\
\hline Heart rate, beats/minute & $90.0(79.0-101.0)$ & $91.5(80.8-107.5)$ & $88.0(75.5-98.0)$ & $0.017 *$ \\
\hline$\geq 100$ & $49(30.1 \%)$ & $32(37.2 \%)$ & $17(22.1 \%)$ & $0.035 \ddagger$ \\
\hline$<100$ & $114(69.9 \%)$ & $54(62.8 \%)$ & $60(77.9 \%)$ & \\
\hline Respiratory rate, breaths/minute & $23.0(20.0-30.0)$ & $23.5(20.0-30.0)$ & $22.0(20.0-30.0)$ & $0.662 *$ \\
\hline$\geq 24$ & $75 / 162(46.3 \%)$ & $43 / 86(50.0 \%)$ & $32 / 76(42.1 \%)$ & $0.315 \ddagger$ \\
\hline$<24$ & $87 / 162(53.7 \%)$ & $43 / 86(50.0 \%)$ & $44 / 76(57.9 \%)$ & \\
\hline Systolic blood pressure, $\mathrm{mmHg}$ & $137.0(120.0-150.0)$ & $131.0(117.8-150.0)$ & $142.0(130.0-152.0)$ & $0.012 *$ \\
\hline Diastolic blood pressure, $\mathrm{mmHg}$ & $80.0(70.0-88.0)$ & $80.0(70.0-89.0)$ & $80.0(72.0-88.0)$ & $0.833^{*}$ \\
\hline $\mathrm{SpO}_{2}, \%$ & $90.0(81.0-95.0)$ & $90.0(82.0-95.0)$ & $91.0(80.0-96.0)$ & $0.936^{*}$ \\
\hline$\geq 93$ & $61(37.4 \%)$ & $32(37.2 \%)$ & $29(37.7 \%)$ & $0.952 \ddagger$ \\
\hline$<93$ & $102(62.6 \%)$ & $54(62.8 \%)$ & $48(62.3 \%)$ & \\
\hline CURB-65 score on admission & $1.0(1.0-2.0)$ & $1.0(1.0-2.0)$ & $1.0(0-2.0)$ & $0.436^{*}$ \\
\hline qSOFA score on admission & $1.0(0-1.0)$ & $1.0(0-1.0)$ & $1.0(0-1.0)$ & $0.139 *$ \\
\hline
\end{tabular}

Note: data are presented as medians (interquartile ranges, IQR), $\mathrm{n}(\%)$ and $\mathrm{n} / \mathrm{N}(\%)$. P values are calculated by Wilcoxon ranksum test, $\chi 2$ test, or Fisher's exact test, as appropriate.

Abbreviations: COPD, chronic obstructive pulmonary disease; $\mathrm{SpO}_{2}$, Oxygen saturation; qSOFA, quick Sequential Organ Failure Assessment.

*Calculated using the Wilcoxon rank-sum test.

$¥$ Calculated using the $\chi 2$ test.

$\S$ Calculated using the Fisher's exact test. 
Table 2. Laboratory findings of younger and elderly deceased patients with COVID-19 on admission.

\begin{tabular}{|c|c|c|c|c|}
\hline Characteristics & Total $(n=163)$ & Younger $(\mathbf{n}=86)$ & Elderly(n=77) & $P$ value \\
\hline White blood cell count, $\times 10^{9} / \mathrm{L}$ & $7.9(5.5-10.8)$ & $7.4(5.3-10.4)$ & $8.3(5.9-10.9)$ & $0.302 *$ \\
\hline Red blood cell count, $\times 10^{12} / \mathrm{L}$ & $4.1(3.8-4.5)$ & $4.1(3.8-4.5)$ & $4.1(3.7-4.5)$ & $0.400 *$ \\
\hline Hemoglobin, g/L & $126.8( \pm 20.0)$ & $126.6( \pm 19.1)$ & $127.1( \pm 21.2)$ & $0.867 \dagger$ \\
\hline Platelet count, $\times 10^{9} / \mathrm{L}$ & $163.50(116.25-231.50)$ & $164.50(109.50-231.50)$ & $161.50(122.00-232.00)$ & $0.905^{*}$ \\
\hline Neutrophil count, $\times 10^{9} / \mathrm{L}$ & $7.01(4.50-9.72)$ & $6.58(4.31-9.30)$ & $7.23(4.68-9.98)$ & $0.335 *$ \\
\hline Lymphocyte count, $\times 10^{9} / \mathrm{L}$ & $0.62(0.46-0.82)$ & $0.57(0.44-0.83)$ & $0.64(0.48-0.82)$ & $0.309 *$ \\
\hline NLR & $10.58(6.77-16.58)$ & $10.60(6.56-16.76)$ & $10.47(6.96-16.03)$ & $0.954 *$ \\
\hline Monocyte count, $\times 10^{9} / \mathrm{L}$ & $0.30(0.20-0.48)$ & $0.30(0.19-0.47)$ & $0.30(0.21-0.50)$ & $0.554 *$ \\
\hline Eosinophil count, $\times 10^{9} / \mathrm{L}$ & $0.00(0.00-0.02)$ & $0.00(0.00-0.01)$ & $0.01(0.00-0.04)$ & $0.019 *$ \\
\hline Basophil count, $\times 10^{9} / \mathrm{L}$ & $0.02(0.01-0.03)$ & $0.02(0.00-0.03)$ & $0.02(0.01-0.03)$ & $0.916^{*}$ \\
\hline Total bilirubin, $\mu \mathrm{mol} / \mathrm{L}$ & $13.45(9.50-20.73)$ & $12.85(9.20-20.05)$ & $14.35(9.83-21.30)$ & $0.562 *$ \\
\hline Direct bilirubin, $\mu \mathrm{mol} / \mathrm{L}$ & $4.90(3.30-8.50)$ & $4.80(3.30-8.35)$ & $5.10(3.50-8.70)$ & $0.719 *$ \\
\hline Alanine aminotransferase, U/L & $36.00(23.25-53.75)$ & $36.50(25.50-55.50)$ & $35.50(18.50-50.00)$ & $0.193 *$ \\
\hline Aspartate aminotransferase, U/L & $44.00(31.00-61.75)$ & $44.00(31.00-61.00)$ & $43.50(29.00-64.50)$ & $0.621 *$ \\
\hline Alkaline phosphatase, U/L & $69.50(48.25-93.00)$ & $72.00(48.25-91.75)$ & $66.00(48.25-94.75)$ & $0.631 *$ \\
\hline$\gamma$-glutamyl transpeptidase, U/L & $41.00(24.25-81.75)$ & $37.00(25.25-94.50)$ & $44.50(23.25-71.00)$ & $0.973 *$ \\
\hline Total protein, $\mathrm{g} / \mathrm{L}$ & $61.30(57.83-64.58)$ & $60.95(57.28-65.18)$ & $61.90(58.30-64.40)$ & $0.798 *$ \\
\hline Albumin, g/L & $28.13( \pm 5.00)$ & $27.99( \pm 4.67)$ & $28.30( \pm 5.38)$ & $0.701 \dagger$ \\
\hline Globin, g/L & $33.20(29.15-37.53)$ & $32.40(29.30-37.68)$ & $33.85(28.95-37.50)$ & $0.965^{*}$ \\
\hline Albumin/globin & $0.80(0.70-1.00)$ & $0.85(0.70-1.00)$ & $0.80(0.70-1.00)$ & $0.890 *$ \\
\hline Prealbumin, mg/L & $85.45(65.83-126.88)$ & $88.20(69.10-129.10)$ & $83.80(58.75-121.85)$ & $0.117 *$ \\
\hline Total bile acid, $\mu \mathrm{mol} / \mathrm{L}$ & $3.20(2.00-5.70)$ & $3.05(1.75-4.40)$ & $3.75(2.18-6.60)$ & $0.056 *$ \\
\hline Creatinine, $\mu \mathrm{mol} / \mathrm{L}$ & $75.4(63.35-95.70)$ & $71.90(56.93-87.98)$ & $80.95(71.10-112.15)$ & $0.001 *$ \\
\hline Blood urea nitrogen, $\mathrm{mmol} / \mathrm{L}$ & $7.02(5.06-10.47)$ & $6.91(4.41-9.16)$ & $7.94(5.43-13.94)$ & $0.016 *$ \\
\hline Uric acid, $\mu \mathrm{mol} / \mathrm{L}$ & $235.05(173.25-331.03)$ & $211.10(158.75-272.70)$ & $273.95(199.38-381.05)$ & $<0.001 *$ \\
\hline Glucose, $\mathrm{mmol} / \mathrm{L}$ & $7.57(6.26-11.02)$ & $7.93(6.50-11.78)$ & $6.99(5.87-10.07)$ & $0.066^{*}$ \\
\hline Creatine kinase, U/L & $\begin{array}{c}132.00(68.50-262.00) \\
(n=134)\end{array}$ & $\begin{array}{c}111.00(71.00-207.25) \\
(\mathrm{n}=72)\end{array}$ & $\begin{array}{c}160.00(57.50-311.75) \\
(\mathrm{n}=62)\end{array}$ & $0.326^{*}$ \\
\hline Lactate dehydrogenase, U/L & $476.00(358.00-591.00)$ & $497.00(381.00-597.75)$ & $472.00(338.00-586.00)$ & $0.604 *$ \\
\hline C-reactive protein, mg/L & $68.88( \pm 43.86)$ & $69.73( \pm 44.45)$ & $67.92( \pm 43.47)$ & $0.799 \dagger$ \\
\hline Procalcitonin, ng/mL & $0.26(0.14-0.45)(n=114)$ & $0.23(0.11-0.41)(n=60)$ & $0.35(0.14-0.76)(n=54)$ & $0.075^{*}$ \\
\hline $\mathrm{D}$-dimer, $\mu \mathrm{g} / \mathrm{mL}$ & $2.31(0.68-8.00)(n=137)$ & $2.68(0.81-8.00)(n=72)$ & $2.07(0.58-8.00)(\mathrm{n}=65)$ & $0.441 *$ \\
\hline Prothrombin time, seconds & $\begin{array}{c}14.20(13.00-15.30) \\
(\mathrm{n}=147)\end{array}$ & $\begin{array}{c}14.20(12.90-15.40) \\
(\mathrm{n}=79)\end{array}$ & $\begin{array}{c}14.20(13.10-15.10) \\
(\mathrm{n}=68)\end{array}$ & $0.529 *$ \\
\hline International normalized ratio & $1.12(1.00-1.24)(\mathrm{n}=148)$ & $1.12(1.00-1.24)(\mathrm{n}=79)$ & $1.12(1.01-1.24)(\mathrm{n}=69)$ & $0.470 *$ \\
\hline $\begin{array}{l}\text { Activated partial thromboplastin } \\
\text { time, seconds }\end{array}$ & $39.19( \pm 8.78)(\mathrm{n}=149)$ & $37.65( \pm 7.89)(n=79)$ & $40.93( \pm 9.45)(n=70)$ & $0.022 \dagger$ \\
\hline Fibrinogen, $g / 1$ & $4.49(3.20-5.25)(n=149)$ & $4.53(3.20-5.38)(n=79)$ & $4.44(3.20-5.25)(\mathrm{n}=70)$ & $0.666^{*}$ \\
\hline Thrombin time, seconds & $\begin{array}{c}15.80(14.95-17.25) \\
(\mathrm{n}=149)\end{array}$ & $\begin{array}{c}15.70\left(\begin{array}{c}(14.90-16.90) \\
(\mathrm{n}=79)\end{array}\right.\end{array}$ & $\begin{array}{c}15.80(15.00-17.30) \\
(\mathrm{n}=70)\end{array}$ & $0.725^{*}$ \\
\hline Brain natriuretic peptide, $\mathrm{pg} / \mathrm{ml}$ & $\begin{array}{c}98.60(39.90-185.40) \\
(\mathrm{n}=89)\end{array}$ & $\begin{array}{c}95.50(39.60-144.80) \\
(\mathrm{n}=47)\end{array}$ & $\begin{array}{c}102.75\left(\begin{array}{c}(41.15-206.13) \\
(\mathrm{n}=42)\end{array}\right.\end{array}$ & $0.562 *$ \\
\hline Myoglobin, $\mathrm{ng} / \mathrm{ml}$ & $\begin{array}{c}127.80(62.85-287.05) \\
(\mathrm{n}=85)\end{array}$ & $\begin{array}{c}98.85(48.90-222.63) \\
(\mathrm{n}=44)\end{array}$ & $\begin{array}{c}171.70(85.25-548.60) \\
(\mathrm{n}=41)\end{array}$ & $0.015^{*}$ \\
\hline Creatine kinase-MB, ng/ml & $1.70(0.90-5.73)(\mathrm{n}=92)$ & $1.50(0.80-4.80)(\mathrm{n}=49)$ & $3.00(0.90-7.00)(n=43)$ & $0.120 *$ \\
\hline $\begin{array}{l}\text { Hypersensitive cardiac troponin } \\
\text { I, ng/L }\end{array}$ & $\begin{array}{c}23.10(8.78-114.18) \\
(\mathrm{n}=92)\end{array}$ & $15.30(7.30-86.40)(\mathrm{n}=47)$ & $\begin{array}{c}41.60(12.75-436.65) \\
(\mathrm{n}=45)\end{array}$ & $0.017 *$ \\
\hline
\end{tabular}

Note: data are presented as mean ( $\pm \mathrm{SD}$ ), medians (interquartile ranges, IQR) and medians (interquartile ranges, IQR) (n). $P$ values are calculated by Wilcoxon rank-sum test or independent group $t$ test, as appropriate.

Abbreviations: NLR, neutrophil-to-lymphocyte ratio.

*Calculated using the Wilcoxon rank-sum test.

+Calculated using the independent group $\mathrm{t}$ test. 
Table 3. CT findings of younger and elderly deceased patients with COVID-19 on admission.

\begin{tabular}{lcccc}
\hline Characteristics & Total $(\mathbf{n}=\mathbf{1 3 9})$ & Younger $(\mathbf{n}=\mathbf{7 4})$ & Elderly(n=65) & P value \\
\hline Lung involvement ratio $(\geq 30 \%)$ & $113(81.3 \%)$ & $58(78.4 \%)$ & $55(84.6 \%)$ & $0.347 \ddagger$ \\
Bilateral lung involvement & $116(83.5 \%)$ & $60(81.1 \%)$ & $56(86.2 \%)$ & $0.422 \ddagger$ \\
Ground-glass opacity & $128(92.1 \%)$ & $69(93.2 \%)$ & $59(90.8 \%)$ & $0.590 \%$ \\
Consolidation & $125(89.9 \%)$ & $65(87.8 \%)$ & $60(92.3 \%)$ & $0.382 \ddagger$ \\
Pleural effusion & $29(20.9 \%)$ & $12(16.2 \%)$ & $17(26.2 \%)$ & $0.150 \%$ \\
Lymphadenopathy & $2(1.4 \%)$ & $1(1.4 \%)$ & $1(1.5 \%)$ & $>0.999 \S$ \\
\hline
\end{tabular}

Note: data are presented as $n$ (\%). $P$ values are calculated by $\chi 2$ test or Fisher's exact test, as appropriate.

$\neq$ Calculated using the $\chi 2$ test.

$\S$ Calculated using the Fisher's exact test.

Table 4. Complications of younger and elderly deceased patients with COVID-19.

\begin{tabular}{lcccc}
\hline Complications & Total $(\mathbf{n = 1 6 3})$ & Younger $(\mathbf{n = 8 6})$ & Elderly $(\mathbf{n = 7 7 )}$ & P value \\
\hline ARDS & $159(97.5 \%)$ & $84(97.7 \%)$ & $75(97.4 \%)$ & $>0.999 \S$ \\
Respiratory failure & $121(74.2 \%)$ & $66(76.7 \%)$ & $55(71.4 \%)$ & $0.439 \ddagger$ \\
Septic shock & $56(34.4 \%)$ & $25(29.1 \%)$ & $31(40.3 \%)$ & $0.133 \ddagger$ \\
Acute cardiac injury & $60(36.8 \%)$ & $37(43.0 \%)$ & $23(29.9 \%)$ & $0.082 \ddagger$ \\
Acute kidney injury & $35(21.5 \%)$ & $18(20.9 \%)$ & $17(22.1 \%)$ & $0.859 \ddagger$ \\
Liver injury & $25(15.3 \%)$ & $12(4.0 \%)$ & $13(16.9 \%)$ & $0.604 \ddagger$ \\
Bacterial infections & $24(14.7 \%)$ & $13(15.1 \%)$ & $11(14.3 \%)$ & $0.881 \ddagger$ \\
Fungal infections & $13(8.0 \%)$ & $4(4.7 \%)$ & $9(11.7 \%)$ & $0.098 \ddagger$ \\
\hline
\end{tabular}

Note: data are presented as $n(\%)$. $P$ values are calculated by $\chi 2$ test or Fisher's exact test, as appropriate.

Abbreviations: ARDS, acute respiratory distress syndrome.

$\neq$ Calculated using the $\chi 2$ test.

$\S$ Calculated using the Fisher's exact test.

Table 5. Univariable and multivariate analyses in factors associated with acute cardiac injury.

\begin{tabular}{lcccc}
\hline Factors & $\begin{array}{c}\text { Univariable OR } \\
(\mathbf{9 5 \%} \text { CI) }\end{array}$ & P value & $\begin{array}{c}\text { Multivariate OR } \\
(\mathbf{9 5 \%} \text { CI) }\end{array}$ & P value \\
\hline Age\# & $0.979(0.953-1.005)$ & 0.116 & $0.968(0.940-0.997)$ & 0.033 \\
Sex (male vs female) & $1.608(0.800-3.232)$ & 0.183 & $1.451(0.696-3.025)$ & 0.321 \\
Hypertension (yes vs no) & $1.523(0.795-2.917)$ & 0.205 & $1.651(0.798-3.415)$ & 0.177 \\
Chronic cardiac injury (yes vs no) & $2.098(0.888-4.957)$ & 0.091 & $2.660(1.034-6.843)$ & 0.042 \\
Diabetes (yes vs no) & $0.689(0.293-1.621)$ & 0.394 & $0.695(0.278-1.735)$ & 0.436 \\
\hline
\end{tabular}

Note: \# Per 1 unit increase.

Abbreviations: $\mathrm{OR}$, odds ratio; $\mathrm{Cl}$, confidence interval.

$\mathrm{P}=0.011$ ) were also associated with an increased likelihood of septic shock. However, age was not associated with septic shock in COVID-19 deceased patients (aOR 1.013, [95\% CI, 0.979-1.048]; $\mathrm{P}=0.462$ ) (Table 6).

\section{DISCUSSION}

Several studies reported that age was an independent risk factor of mortality in patients with COVID-19 [6-9, 13]. This study found that younger deceased patients were more likely to develop fever than elderly deceased patients were. Anorexia was, however, more common in elderly deceased patients than younger deceased patients. We also found that younger deceased patients were more likely to develop an acute cardiac injury.

The mortality rate in our study was at $12.12 \%$, which is much higher than the current national reports (4634/84981, 5.45\%) [3]. This might be related to the following reasons. First, Union Hospital West Campus was a designed hospital for severely or critically ill 
Table 6. Univariable and multivariate analyses in factors associated with septic shock.

\begin{tabular}{lcccc}
\hline Factors & $\begin{array}{c}\text { Univariable OR } \\
(\mathbf{9 5 \%} \text { CI) }\end{array}$ & P value & $\begin{array}{c}\text { Multivariate OR } \\
(\mathbf{9 5 \%} \text { CI) }\end{array}$ & P value \\
\hline Age\# & $1.017(0.990-1.046)$ & 0.222 & $1.013(0.979-1.048)$ & 0.462 \\
Bacterial infections (yes vs no) & $73.879(9.607-568.107)$ & $<0.001$ & $66.304(8.490-517.785)$ & $<0.001$ \\
Fungal infections (yes vs no) & $12.833(2.733-60.257)$ & 0.001 & $8.946(1.654-48.380)$ & 0.011 \\
\hline
\end{tabular}

Note: \# Per 1 unit increase.

Abbreviations: $\mathrm{OR}$, odds ratio; $\mathrm{Cl}$, confidence interval.

patients with COVID-19 in Wuhan, China. Some severely or critically ill patients were transferred from other hospitals, which led to a relatively high mortality rate. Secondly, as the spread of the virus was well controlled in the late stage and with improved virus detection rate, patients with COVID-19 could be treated in a timely and effective manner.

A previous study demonstrated that the infection fatality ratio for individuals 70 years and older was $10.5 \%$ while for those patients younger than 70 years was $0.43 \%$ [14]. Age-related diseases and vulnerability to COVID-19 are highly intertwined [15]. Indeed, this study showed that elderly deceased patients presented with hypertension, COPD, and chronic cardiac disease more frequently. Previous studies showed that the most commonly observed comorbidity in patients with COVID-19 was hypertension [16, 17]. This is similar to our study. However, considering that age was reported to be an independent risk factor of poor outcomes in patients with COVID-19 [6-9, 13], aging, and its related mechanisms may play an important role in disease severity of COVID-19.

The most common symptoms of the 163 deceased patients were fever, dyspnea, cough, fatigue, and shortness of breath, which were similar to other researches [18, 19]. However, in our study, fever was more frequent in younger deceased patients while anorexia was more frequent in elderly deceased patients. These results indicate that there might be some differences in disease pathogenesis and progression between the younger and elderly deceased patients. A possible hypothesis is that in critically ill COVID-19 patients, cellular hyperfunctions of elderly deceased patients were more likely to switch to cellular exhaustion, and loss of functions at late stages [15].

The main cause of death in both groups was ARDS and respiratory failure. However, acute cardiac injury also plays an important role in in-hospital mortality in patients with COVID-19 [20]. The mechanisms of cardiac injury are however not yet well established, but are likely to involve increased cardiac stress due to respiratory failure and hypoxemia, direct myocardial infection by SARS-CoV-2, indirect injury from the systemic inflammatory response, or a combination of all three factors $[21,22]$. It has been reported that SARS$\mathrm{CoV}-2$ could be detected within the myocardium of deceased patients but the presence of SARS-CoV-2 was not associated with an influx of inflammatory cells [23]. These results might suggest that myocardial injury is likely related to systemic consequences rather than direct damage caused by SARS-CoV-2 [24]. It has been reported that older COVID-19 patients were more likely to develop an acute cardiac injury [25]. However, a previous study demonstrated that cardiovascular comorbidities increased relative risks for adverse outcomes most substantially in the younger COVID-19 patients with progressively diminishing relative effects in older ages [26]. In our study, we found that age was a protective factor for the acute cardiac injury of deceased patients. These results indicated that despite the lower incidences of acute cardiac injury in younger patients, it is vital to prevent acute cardiac injury in younger patients. Moreover, once a younger patient developed an acute cardiac injury, more attention should be paid to prevent the adverse outcomes caused by the cardiac injury.

Our study had several limitations. Firstly, it was retrospective and all data was collected from case records. In addition, some important indicators such as the immunological index, and treatment history of patients were not collected in our study. Secondly, ours is a single-center study, although the health-care workers were from all over the country, hence some factors including the bacteria colonizing the hospital might be different. Thirdly, Union Hospital West Campus was a designated hospital for severely or critically ill COVID-19 patients in Wuhan, China. Consequently, there might be some selection bias, and therefore the external validity of the conclusions needs to be further validated.

In summary, this study described the clinical characteristics of younger and elderly deceased COVID-19 patients. We established that younger deceased patients were more likely to develop fever than elderly deceased patients were while anorexia was more common in elderly deceased patients than in younger deceased patients. The multivariate logistic 
regression analysis showed that younger deceased patients were more likely to develop an acute cardiac injury. Moreover, this study demonstrated that it is important to monitor cardiac function and prevent acute cardiac injury in severely and critically ill patients with COVID-19 regardless of age.

\section{MATERIALS AND METHODS}

\section{Study design and participants}

This single-center, retrospective study was conducted at Wuhan Union Hospital West Campus, a designated hospital for severely and critically ill COVID-19 patient treatment. This study was approved by the Institutional Ethics Committee of Union Hospital, Tongji Medical College, Huazhong University of Science and Technology (NO.20200036), and the requirement for informed consent was exempted by the Ethics Committee.
The inclusion criteria were adult deceased patients with confirmed COVID-19 who had been hospitalized for more than 48 hours. From January 12, 2020, to March 30, 2020, a total of 1671 adult patients with suspected and confirmed COVID-19 were admitted to Wuhan Union Hospital West Campus. Among them, 1584 were confirmed cases, $192 \quad(12.12 \%$, [95\% confidence interval (CI), 10.60\%-13.82\%]) patients with confirmed COVID-19 died until April 22, 2020. Among the 192 deceased patients, 29 died within 48 hours of admission and were excluded from the study. Finally, a total of 163 deceased patients were enrolled in this study (Figure 1).

\section{Definitions}

The diagnosis of COVID-19 was based on the guidelines of the diagnosis and treatment of new coronavirus pneumonia (version 7) published by the National Health Commission of China [27]. Acute

1671 adult patients with suspected and confirmed Coronavirus disease 2019 (COVID-19) admitted in Wuhan Union Hospital West Campus from January 12, 2020 to March 30, 2020

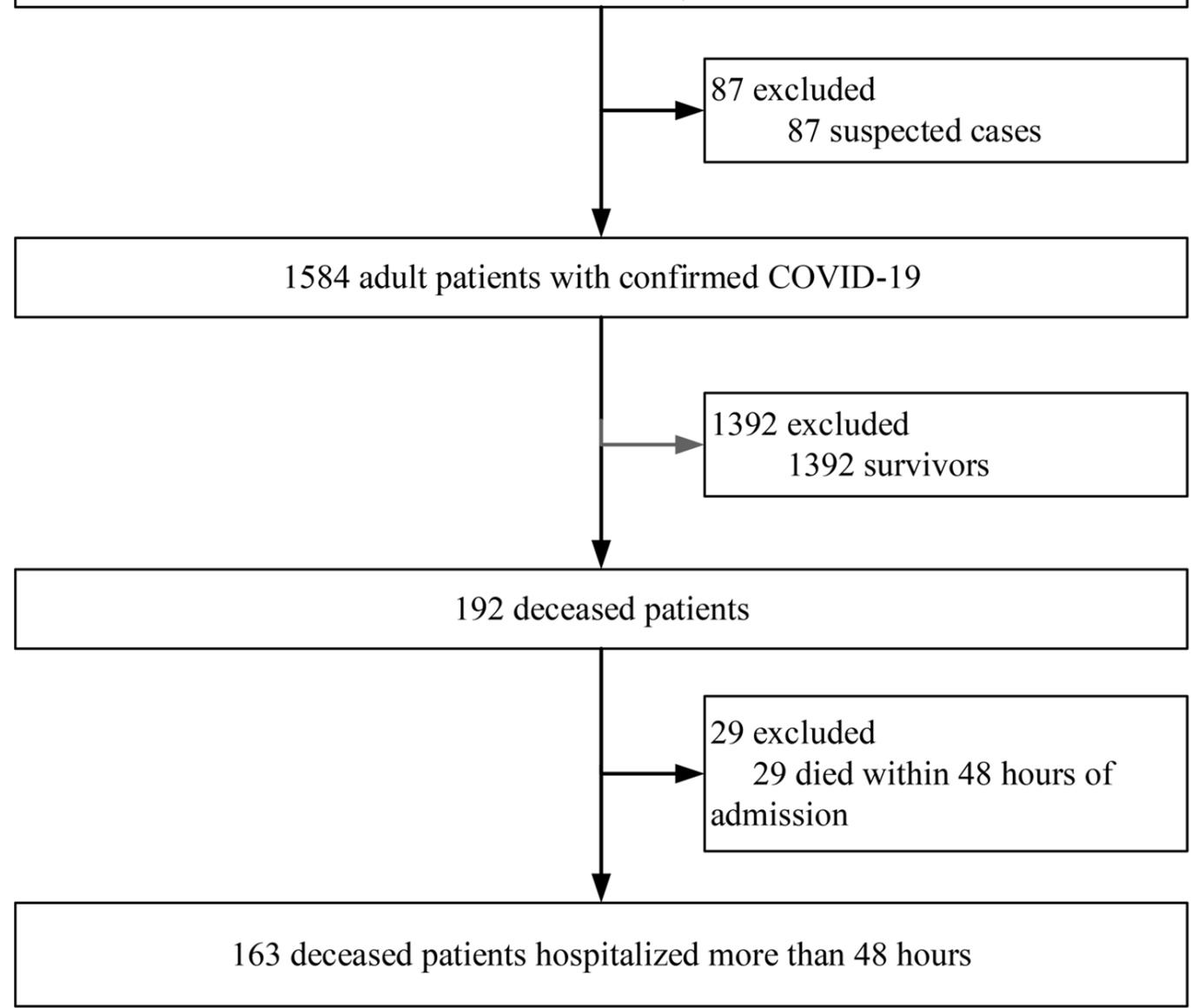

Figure 1. Flow diagram of patient selection. 
respiratory distress syndrome (ARDS) was diagnosed according to the Berlin Definition [28]. Septic shock was defined according to The Third International Consensus Definitions for Sepsis and Septic Shock (Sepsis-3) [29]. Acute kidney injury was diagnosed according to the KDIGO clinical practice guidelines [30]. Acute cardiac injury was diagnosed according to the COVID-19 rapid guideline: acute myocardial injury [31]. Patients with Brain Natriuretic Peptide (BNP) level above $250 \mathrm{pg} / \mathrm{ml}$ were also diagnosed as having a cardiac injury [32]. Acute liver injury was diagnosed as previously described [10].

\section{Data collection}

We collected all available information from the medical records in the hospital. This included the epidemiological history, clinical, laboratory, radiological characteristics, and outcomes. All data collected from electronic medical records were then recorded into a standardized form and checked by professional clinicians to verify the accuracy of the data.

\section{Factors enrolled in multivariate analyses}

Least Absolute Shrinkage and Selection Operator (LASSO) regression was applied to minimize the potential collinearity of variables measured from the same patient and over-fitting of variables as previously described [33]. In LASSO regression, the performance of the model was augmented with 10 -fold cross-validation and the covariates were selected by the minimum $(\lambda$ min). This regression model penalizes the absolute size of the coefficients of a regression model based on the value of $\lambda$. With larger penalties, the estimates of weaker factors shrink toward zero, so that only the strongest factors remain in the model. For respiratory failure, six variables (age, sex, COPD, hypertension, chronic cardiac disease, and diabetes) were selected to enroll into the LASSO regression model but no variables were available for further analysis. For acute cardiac injury, five variables (age, sex, hypertension, chronic cardiac disease, and diabetes) were selected to enroll into the LASSO regression model. All five variables were selected for further multivariable analysis. For septic shock, five variables (age, sex, bacterial infections, fungal infections, and diabetes) were selected to enroll into the LASSO regression model. Age, bacterial infections, and fungal infections were selected for further multivariable analysis. For acute kidney injury, six variables (age, sex, chronic kidney disease, hypertension, chronic cardiac disease, and diabetes) were selected to enroll into the LASSO regression model but no variables were available for further analysis. Other complications including liver injury and gastrointestinal bleeding were not available for multivariable analysis.

\section{Statistical analysis}

Categorical variables were presented as frequency rates and percentages, and continuous variables were expressed as mean \pm standard deviation (SD) if they were normally distributed or median (interquartile range $[\mathrm{IQR}]$ ) if they were not. Proportions for categorical variables were compared using the $\chi 2$ test or Fisher's exact test. Besides, means for continuous variables were compared using independent group $\mathrm{t}$ test when the data was normally distributed. Otherwise, the Wilcoxon rank-sum test was employed. A $95 \%$ confidence interval (CI) of mortality was analyzed by Wilson Score CI. All statistics were twotailed and a $\mathrm{P}$ value less than 0.05 was considered as significant. All statistical analyses were performed using SPSS software (version 22.0).

\section{AUTHOR CONTRIBUTIONS}

YJ, XT and SZ contributed to the study design. JX, LD, $\mathrm{HX}$ and $\mathrm{ZY}$ collected the epidemiological and clinical data. MZ, QH, ZL and WX summarized all data. XT and SZ performed the statistical analysis. XT, SZ and JX drafted the manuscript and supervised the entire study. All authors critically reviewed the manuscript and approved the final draft.

\section{ACKNOWLEDGMENTS}

We thank all the patients who consented to donate their data for analysis and the medical staff members who are on the front line of caring for patients.

\section{CONFLICTS OF INTEREST}

All authors declare that there are no conflicts of interest.

\section{FUNDING}

This work was supported by the National Natural Science Special Foundation of China for COVID-19 (NO.82041018) and the Independent Innovation Research Fund for Huazhong University of Science and Technology (2020kfyXGYJ).

\section{REFERENCES}

1. Wu F, Zhao S, Yu B, Chen YM, Wang $W$, Song ZG, Hu Y, Tao ZW, Tian JH, Pei YY, Yuan ML, Zhang YL, Dai $\mathrm{FH}$, et al. A new coronavirus associated with human respiratory disease in China. Nature. 2020; 579:265-269. https://doi.org/10.1038/s41586-020-2008-3 PMID: $\underline{32015508}$ 
2. World Health Organization. Coronavirus disease (COVID-19) Weekly Epidemiological Update. https://www.who.int/docs/default-

source/coronaviruse/situation-reports/20200824weekly-epi-update.pdf?sfvrsn=806986d1 4.

3. National Health Commission of the People's Republic of China. Coronavirus disease 2019 situation report. http://www.nhc.gov.cn/xcs/yqtb/202008/34a1d6028a 3449d0b2c2679c5d8e3b1b.shtml.

4. Yang $X, Y u Y, X u$ J, Shu H, Xia J, Liu H, Wu Y, Zhang L, Yu $Z$, Fang $M, Y u T$, Wang $Y$, Pan $S$, et al. Clinical course and outcomes of critically ill patients with SARS-CoV-2 pneumonia in Wuhan, China: a single-centered, retrospective, observational study. Lancet Respir Med. 2020; 8:475-81.

https://doi.org/10.1016/S2213-2600(20)30079-5 PMID:32105632

5. Nachtigall I, Lenga $P$, Jóźwiak $K$, Thürmann $P$, MeierHellmann A, Kuhlen R, Brederlau J, Bauer T, Tebbenjohanns J, Schwegmann K, Hauptmann M, Dengler J. Clinical course and factors associated with outcomes among 1904 patients hospitalized with COVID-19 in Germany: an observational study. Clin Microbiol Infect. 2020. [Epub ahead of print]. https://doi.org/10.1016/i.cmi.2020.08.011 PMID:32822883

6. Xu J, Yang $X$, Yang L, Zou X, Wang $Y$, Wu Y, Zhou T, Yuan Y, Qi H, Fu S, Liu H, Xia J, Xu Z, et al. Clinical course and predictors of 60-day mortality in 239 critically ill patients with COVID-19: a multicenter retrospective study from Wuhan, China. Crit Care. 2020; 24:394.

https://doi.org/10.1186/s13054-020-03098-9 PMID:32631393

7. Zhou F, Yu T, Du R, Fan G, Liu Y, Liu Z, Xiang J, Wang Y, Song B, Gu X, Guan L, Wei Y, Li H, et al. Clinical course and risk factors for mortality of adult inpatients with COVID-19 in Wuhan, China: a retrospective cohort study. Lancet. 2020; 395:1054-62.

https://doi.org/10.1016/S0140-6736(20)30566-3 PMID: $\underline{32171076}$

8. Zhang S, Guo M, Duan L, Wu F, Hu G, Wang Z, Huang Q, Liao T, Xu J, Ma Y, Lv Z, Xiao W, Zhao Z, et al. Development and validation of a risk factor-based system to predict short-term survival in adult hospitalized patients with COVID-19: a multicenter, retrospective, cohort study. Crit Care. 2020; 24:438.

https://doi.org/10.1186/s13054-020-03123-x PMID:32678040

9. Cen $Y$, Chen $X$, Shen $Y$, Zhang $X H$, Lei $Y, X u C$, Jiang WR, Xu HT, Chen Y, Zhu J, Zhang LL, Liu YH. Risk factors for disease progression in patients with mild to moderate coronavirus disease 2019-a multi-centre observational study. Clin Microbiol Infect. 2020; 26:1242-47. https://doi.org/10.1016/j.cmi.2020.05.041 PMID: $\underline{32526275}$

10. Chen T, Wu D, Chen H, Yan W, Yang D, Chen G, Ma K, Xu D, Yu H, Wang H, Wang T, Guo W, Chen J, et al. Clinical characteristics of 113 deceased patients with coronavirus disease 2019: retrospective study. BMJ. 2020; 368:m1091. https://doi.org/10.1136/bmj.m1091 PMID:32217556

11. Wang B, Van Oekelen O, Mouhieddine TH, Del Valle DM, Richter J, Cho HJ, Richard S, Chari A, Gnjatic S, Merad M, Jagannath S, Parekh S, Madduri D. A tertiary center experience of multiple myeloma patients with COVID-19: lessons learned and the path forward. J Hematol Oncol. 2020; 13:94.

https://doi.org/10.1186/s13045-020-00934-x PMID:32664919

12. Shi $Q$, Zhang $X$, Jiang $F$, Zhang $X$, Hu N, Bimu C, Feng J, Yan S, Guan Y, Xu D, He G, Chen C, Xiong X, et al. Clinical characteristics and risk factors for mortality of COVID-19 patients with diabetes in Wuhan, China: a two-center, retrospective study. Diabetes Care. 2020; 43:1382-91.

https://doi.org/10.2337/dc20-0598

PMID:32409504

13. Cummings MJ, Baldwin MR, Abrams D, Jacobson SD, Meyer BJ, Balough EM, Aaron JG, Claassen J, Rabbani LE, Hastie J, Hochman BR, Salazar-Schicchi J, Yip NH, et al. Epidemiology, clinical course, and outcomes of critically ill adults with COVID-19 in New York City: a prospective cohort study. Lancet. 2020; 395:1763-70. https://doi.org/10.1016/S0140-6736(20)31189-2 PMID:32442528

14. Poletti P, Tirani M, Cereda D, Trentini F, Guzzetta G, Marziano V, Buoro S, Riboli S, Crottogini L, Piccarreta R, Piatti A, Grasselli G, Melegaro A, et al. Age-specific SARS-CoV-2 infection fatality ratio and associated risk factors, Italy, February to April 2020. Euro Surveill. 2020; 25:2001383.

https://doi.org/10.2807/1560-7917.ES.2020.25.31. 2001383 PMID: $\underline{32762797}$

15. Blagosklonny MV. From causes of aging to death from COVID-19. Aging (Albany NY). 2020; 12:10004-21. https://doi.org/10.18632/aging.103493 PMID:32534452

16. Grasselli G, Zangrillo A, Zanella A, Antonelli M, Cabrini L, Castelli A, Cereda D, Coluccello A, Foti G, Fumagalli R, lotti G, Latronico N, Lorini L, et al, and COVID-19 Lombardy ICU Network. Baseline characteristics and outcomes of 1591 patients infected with SARS-CoV-2 admitted to ICUs of the Lombardy region, Italy. JAMA. 2020; 323:1574-81.

https://doi.org/10.1001/jama.2020.5394

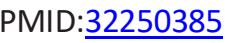


17. Shi $Y$, Yu X, Zhao H, Wang $H$, Zhao R, Sheng J. Host susceptibility to severe COVID-19 and establishment of a host risk score: findings of 487 cases outside Wuhan. Crit Care. 2020; 24:108.

https://doi.org/10.1186/s13054-020-2833-7

PMID: 32188484

18. Guan WJ, Ni ZY, Hu Y, Liang $W H, O u C Q$, He JX, Liu L, Shan H, Lei CL, Hui DS, Du B, Li LJ, Zeng G, et al, and China Medical Treatment Expert Group for Covid-19. Clinical characteristics of coronavirus disease 2019 in China. N Engl J Med. 2020; 382:1708-20.

https://doi.org/10.1056/NEJMoa2002032 PMID:32109013

19. Huang $C$, Wang $Y$, Li X, Ren L, Zhao J, Hu Y, Zhang L, Fan G, Xu J, Gu X, Cheng Z, Yu T, Xia J, et al. Clinical features of patients infected with 2019 novel coronavirus in Wuhan, China. Lancet. 2020; 395:497-506.

https://doi.org/10.1016/S0140-6736(20)30183-5 PMID:31986264

20. Shi S, Qin M, Shen B, Cai Y, Liu T, Yang F, Gong W, Liu X, Liang J, Zhao $Q$, Huang $H$, Yang B, Huang C. Association of Cardiac Injury With Mortality in Hospitalized Patients With COVID-19 in Wuhan, China. JAMA Cardiol. 2020; 5:802-810.

https://doi.org/10.1001/jamacardio.2020.0950 PMID:32211816

21. Clerkin KJ, Fried JA, Raikhelkar J, Sayer G, Griffin JM, Masoumi A, Jain SS, Burkhoff D, Kumaraiah D, Rabbani L, Schwartz A, Uriel N. COVID-19 and cardiovascular disease. Circulation. 2020; 141:1648-55.

https://doi.org/10.1161/CIRCULATIONAHA.120.046941 PMID: $\underline{32200663}$

22. Zheng YY, Ma YT, Zhang JY, Xie X. COVID-19 and the cardiovascular system. Nat Rev Cardiol. 2020; 17:259-60.

https://doi.org/10.1038/s41569-020-0360-5 PMID:32139904

23. Lindner $D$, Fitzek $A$, Bräuninger $H$, Aleshcheva $G$, Edler C, Meissner K, Scherschel K, Kirchhof P, Escher F, Schultheiss HP, Blankenberg S, Püschel K, Westermann D. Association of cardiac infection with SARS-CoV-2 in confirmed COVID-19 autopsy cases. JAMA Cardiol. 2020; 5:1281-85.

https://doi.org/10.1001/jamacardio.2020.3551 PMID:32730555

24. Deng $Q$, Hu B, Zhang $Y$, Wang H, Zhou X, Hu W, Cheng $Y$, Yan J, Ping $H$, Zhou Q. Suspected myocardial injury in patients with COVID-19: evidence from front-line clinical observation in Wuhan, China. Int J Cardiol. 2020; 311:116-21.

https://doi.org/10.1016/j.ijcard.2020.03.087

PMID:32291207
25. Barman HA, Atici A, Sahin I, Alici G, Aktas Tekin E, Baycan ÖF, Ozturk F, Oflar E, Tugrul S, Yavuz MB, Celik $\mathrm{FB}$, Oktay A, Vahaboglu $\mathrm{H}$, et al. Prognostic significance of cardiac injury in COVID-19 patients with and without coronary artery disease. Coron Artery Dis. 2020; 10:1097.

https://doi.org/10.1097/MCA.0000000000000914 PMID:32568741

26. Kuno $T$, Takahashi $M$, Obata $R$, Maeda $T$. Cardiovascular comorbidities, cardiac injury, and prognosis of COVID-19 in New York City. Am Heart J. 2020; 226:24-25.

https://doi.org/10.1016/j.ahj.2020.05.005

PMID:32425197

27. National Health Commission of China. The Guidelines of the Diagnosis and Treatment of New Coronavirus Pneumonia (version7). http://www.gov.cn/zhengce/ zhengceku/2020-03/04/content 5486705.htm.

28. Ranieri VM, Rubenfeld GD, Thompson BT, Ferguson ND, Caldwell E, Fan E, Camporota L, Slutsky AS, and ARDS Definition Task Force. Acute respiratory distress syndrome: the Berlin definition. JAMA. 2012; 307:2526-33.

https://doi.org/10.1001/jama.2012.5669

PMID:22797452

29. Singer M, Deutschman CS, Seymour CW, Shankar-Hari M, Annane D, Bauer M, Bellomo R, Bernard GR, Chiche JD, Coopersmith CM, Hotchkiss RS, Levy MM, Marshall $J C$, et al. The third international consensus definitions for sepsis and septic shock (Sepsis-3). JAMA. 2016; 315:801-10.

https://doi.org/10.1001/jama.2016.0287

PMID:26903338

30. Khwaja A. KDIGO clinical practice guidelines for acute kidney injury. Nephron Clin Pract. 2012; 120:c179-84. https://doi.org/10.1159/000339789 PMID:22890468

31. COVID-19 rapid guideline: acute myocardial injury. https://www.nice.org.uk/guidance/ng171/resources/a cute-myocardial-injury-algorithm-pdf-8717541373.

32. McQuade CN, Mizus M, Wald JW, Goldberg L, Jessup $M$, Umscheid CA. Brain-type natriuretic peptide and amino-terminal pro-brain-type natriuretic peptide discharge thresholds for acute decompensated heart failure: a systematic review. Ann Intern Med. 2017; 166:180-90.

https://doi.org/10.7326/M16-1468 PMID:27894126

33. Liang W, Liang H, Ou L, Chen B, Chen A, Li C, Li Y, Guan W, Sang L, Lu J, Xu Y, Chen G, Guo H, et al, and China Medical Treatment Expert Group for COVID-19. Development and validation of a clinical risk score to predict the occurrence of critical illness in hospitalized 
patients with COVID-19. JAMA Intern Med. 2020; 180:1081-89.

https://doi.org/10.1001/jamainternmed.2020.2033

PMID: $\underline{32396163}$ 